\title{
Correlates of extinction risk in Chinese endemic birds
}

\author{
Chuanwu Chen ${ }^{1}$, Di Zeng ${ }^{2}$, Yuhao Zhao ${ }^{2}$, Yiru Wu ${ }^{2}$, Junfeng $X u^{3}$ and Yanping Wang ${ }^{1,2^{*}}$
}

\begin{abstract}
Background: China has a relative high degree of endemism of birds due to its large area, diversified topography, and varied climates and habitats. Among the 77 Chinese endemic birds, 29 species are classified as threatened according to the officially released China Biodiversity Red List in 2015. Chinese endemic birds should be the focus of conservation because their local extinction in China means complete global extinction. However, to date, no study has explicitly examined the patterns and processes of extinction and threat in Chinese endemic birds.

Methods: We obtained eleven biological traits and four extrinsic factors that are commonly hypothesized to influence extinction risk. After phylogenetic correction, these factors were used separately and in combination to assess their associations with extinction risk.
\end{abstract}

Results: We found that $37.7 \%$ of Chinese endemic birds were listed as threatened (Vulnerable, Endangered and Critically Endangered). Small range size, high hunting vulnerability, and high human population density were important predictors of high extinction risk in Chinese endemic birds.

Conclusions: Our study is the first to systematically investigate the patterns and processes of extinction risk in Chinese endemic birds. We suggest that endemic species with small range size and living in area with high human densities require conservation priorities. Conservation efforts should also focus on the reduction of human threats, such as human hunting and habitat degradation, for the effective preservation of Chinese endemic birds.

Keywords: Comparative analysis, Endemic birds, Geographic range size, Human population density, Hunting vulnerability, Proactive conservation, Red list

\section{Background}

Endemic species are those which are only found in a specified location or region and nowhere else in the world (Darlington 1957; Isik 2011). Endemic species can have a high risk of extinction simply by chance alone (Gaston 1994). Endemic species are also vulnerable to extinction because they are confined to limited geographic ranges; they often have small range and population sizes, and sometimes low genetic diversity and specific habitat requirements (Gaston 1994; Myers et al. 2000; Isik 2011). Endemic species have been used as an important criterion to determine biodiversity hotspots and conservation

\footnotetext{
*Correspondence: wangyp214@gmail.com

1 Jiangsu Key Laboratory for Biodiversity and Biotechnology, College of Life Sciences, Nanjing Normal University, Nanjing 210023, China Full list of author information is available at the end of the article
}

priorities (Myers et al. 2000; Rabitsch et al. 2016). Understanding the patterns and underlying processes of extinction risk in endemic species would facilitate proactive conservation efforts.

China is one of the countries with the richest bird biodiversity in the world (Zheng 2011). With its large area, diversified topography, and varied climates and habitats, China has a relative high degree of endemism of birds (Lei and Lu 2006). Among the 1372 Chinese birds, 77 species were strictly endemic to China (Zheng 2011). However, a large proportion (29 species) of the Chinese endemic birds are classified as threatened (Zhang et al. 2016) according to the officially released China Biodiversity Red List in 2015 (MEP and CAS 2015). Habitat loss and degradation, hunting and trade, and human activities such as dam-construction and tourism are listed as three major threats that endanger Chinese endemic 
birds (reviewed by Zheng 2015; Zhang et al. 2016). Previous studies of Chinese endemic birds are focused on the identification of areas of endemism and conservation hotspots (Lei et al. 2003a, b). Chinese endemic birds should be the focus of conservation because their local extinction in China means complete global extinction. However, to date, no study has explicitly examined the patterns and processes of extinction and threat in Chinese endemic birds.

The extinction of species is influenced both by intrinsic factors and extrinsic processes. Previous analyses of extinction risk in vertebrates worldwide have largely focused on how intrinsic factors are related to species threat status (e.g. Gaston and Blackburn 1995; Purvis et al. 2000; Jones et al. 2003; Wang et al. 2018). For birds, body size, clutch size, geographical range size, trophic level, dispersal ability, habitat and social specialization, nesting site, nesting type, migratory status and hunting vulnerability have been identified as important intrinsic risk factors (Terborgh 1974; Wilcove 1985; Bennett and Owens 1997; Van Houtan et al. 2006; Sodhi et al. 2010; Wang et al. 2018). A number of extrinsic factors, such as human population density, temperature, productive energy (NDVI) and elevation, are also linked to species extinction risk (Cardillo et al. 2004; Collen et al. 2006; Davies et al. 2006; Lee and Jetz 2011). However, to successfully predict extinct risk, some studies have highlighted the importance of modelling extrinsic and intrinsic factors together (Fisher et al. 2003; Isaac and Cowlishaw 2004; Cardillo et al. 2008; Murray et al. 2014; Böhm et al. 2016).

In this study, we conducted the first extensive analysis to systematically investigate the patterns and processes of extinction and threat in Chinese endemic birds. The following two questions were addressed. First, what is the pattern of extinction risk in Chinese endemic birds? Second, which biological traits and extrinsic factors are correlated with extinction risk in Chinese endemic birds? Identifying key correlates of extinction risk in Chinese endemic birds is important for their proactive conservation and can be used to help direct management efforts.

\section{Methods}

\section{Data collection}

We derived all measures of extinction risk from the recently released China Biodiversity Red List (MEP and CAS 2015). The China Biodiversity Red List evaluates the risk of extinction for Chinese species mainly using the IUCN Red List Categories and Criteria (Version 3.1) (IUCN 2012a) and Guidelines for Application of IUCN Red List Criteria at Regional and National Levels (Version 4.0) (IUCN 2012b). It comprehensively evaluated the status of all the 1372 Chinese bird species for the first time (Zhang et al. 2016). Following Purvis et al. (2000), extinction risk was recorded as Least Concern $(\mathrm{LC})=0$, Near Threatened $(\mathrm{NT})=1$, Vulnerable $(\mathrm{VU})=2$, Endangered $(\mathrm{EN})=3$, Critically Endangered $(\mathrm{CR})=4$, and Extinct (EX) or Regionally Extinct $(\mathrm{RE})=5$. Regionally Extinct, which is applicable only to regional levels, is one of the main differences in threat categories between the IUCN and regional Red Lists (IUCN 2012b).

We used China Biodiversity Red List (MEP and CAS 2015), rather than IUCN Red List, to measure the extinction risk of Chinese endemic birds for three reasons. First, as these bird species are endemic to China, China Biodiversity Red List was the most appropriate scale (Milner-Gulland et al. 2006), and therefore gave a better representation of the status of endemic birds within China than the IUCN Red List (MEP and CAS 2015). Furthermore, other regional or national Red List studies often meet several problems not experienced with global listing, including how to deal with cross border populations and nonbreeding phases that are nevertheless dependent on the region for certain resources (Collen et al. 2006; Milner-Gulland et al. 2006; IUCN 2012b). However, as Chinese endemic birds occurred only in China, the above confounding problems did not exist in our study. Finally, data quality and availability for bird species at the national scale are often better than those of global scale (Zhang et al. 2016). This makes the national assessment more accurate and more practical for the conservation of these endemic species in China.

We omitted two data deficient (DD) species (Caprimulgus centralasicus and Leucosticte sillemi) from our analyses. Accordingly, a total of 75 species were retained in extinction risk analyses (Additional file 1: Appendix S1). We built a phylogenetic tree for these 75 species (Fig. 1), following the method of Jetz et al. (2012). To obtain the phylogenetic tree, we pruned the global phylogenetic tree of birds from BirdTree (http://birdtree.org) under the option of "Hackett All Species: a set of 10,000 trees with 9993 OTUs each" to include these 75 Chinese birds (Jetz et al. 2012). We sampled 5000 pseudo-posterior distributions and constructed the Maximum Clade Credibility tree using mean node heights by the program TreeAnnotator (BEAST v 1.8.2; Drummond and Rambaut 2007).

We collected data on eleven life-history and ecological traits for each species using the published literature. These traits were selected because they are commonly hypothesized to influence extinction risk in birds based on empirical and theoretical evidence (Terborgh 1974; Wilcove 1985; Bennett and Owens 1997; Van Houtan et al. 2006; Sodhi et al. 2010; Wang et al. 2018). We used body length $(\mathrm{mm})$ to represent body size (Wang et al. 2015). Clutch size was defined as the median number of eggs per nest (Sodhi et al. 2010). Trophic guilds 


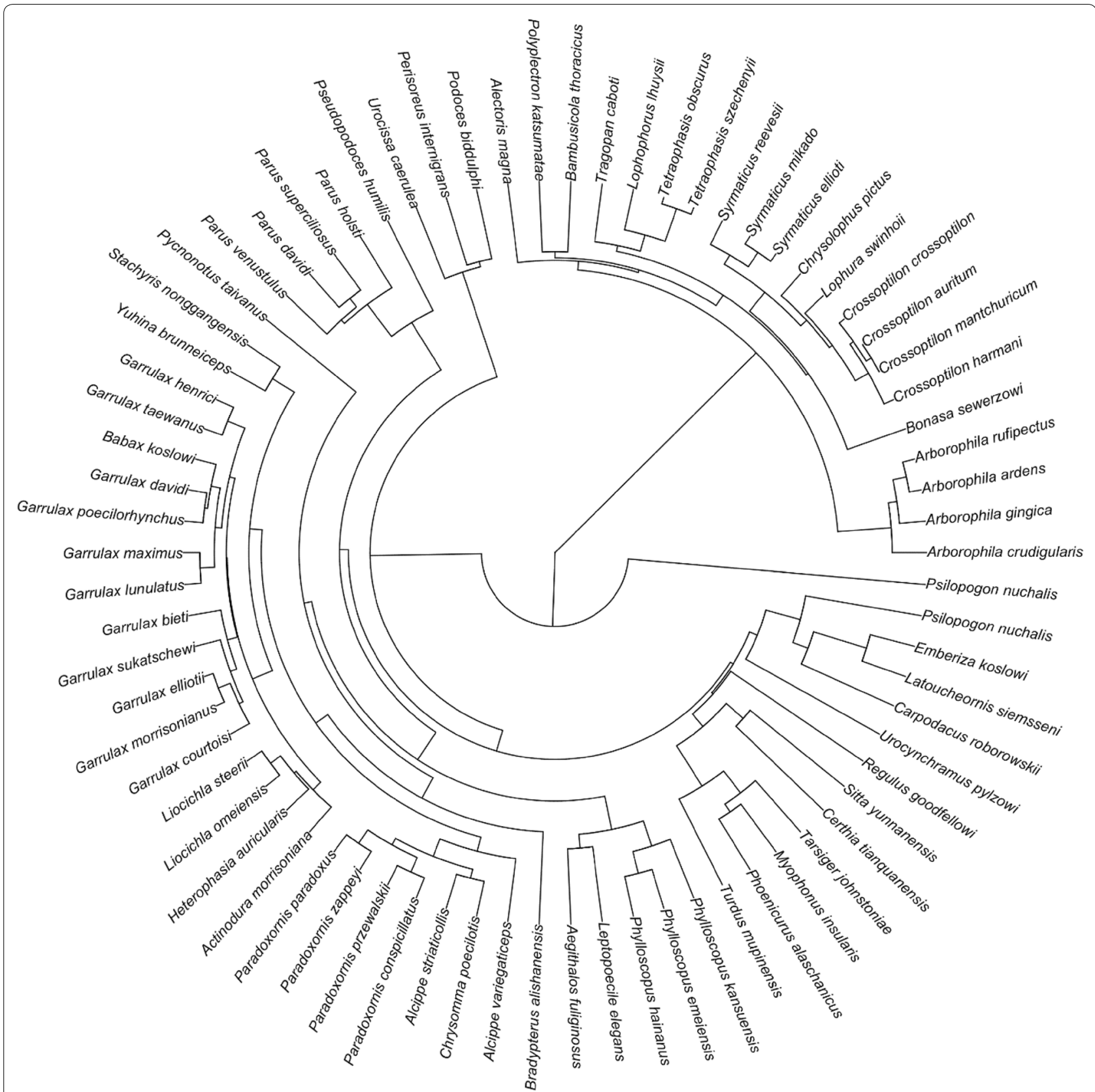

Fig. 1 Phylogenetic tree of the 75 Chinese endemic bird species used in the comparative analysis. The phylogeny is built following the tree construction method of Jetz et al. (2012)

were quantified as omnivores (1), granivores (2), frugivores (3), and insectivores (4) (Sekercioglu et al. 2002). We obtained the geographic range size $\left(\mathrm{km}^{2}\right)$ from published species range maps (Zheng 2011) by digitizing the area into an ArcGIS Release 10.2 (ESRI 2016). However, $\mathrm{Li}$ and Pimm (2016) highlighted that it is important to refine each species' range by elevation and habitat to get a more precise measurement. We thus obtained refined geographic range size of endemic birds based on their elevation ranges (Additional file 1: Appendix S1). The elevational data were collected from BirdLife International and the IUCN Red List (Li and Pimm 2016). To obtain an index of a species' mobility, we calculated a dispersal ratio (dp) for each species by dividing its mean wing length $(\mathrm{mm})$ by the cube root of its mean mass (g) (Woinarski 1989). Nest type was classified as exposed (no nest, 
platform, saucer, scrape) (1) or not (0) (Sodhi et al. 2010). Nest substrate was classified as cavity (1), tree (2), shrub (3), and ground (4) (Barbaro and van Halder 2009). We used the IUCN Habitats Classification Scheme to classify habitats (http://www.iucnredlist.org/technical-docum ents/classification-schemes/habitats-classification-schem e-ver3) (Newbold et al. 2013). Habitat specificity was then calculated as the number of habitats a species has been recorded in (Sodhi et al. 2010). Flocking tendencies were classified as strictly solitary (0), occasionally social (1), and strictly social (2) (Beauchamp 2004). Migrant status was classified as resident (0), partial migrant (1), and full migrant (2) (Van Turnhout et al. 2010). Following Thornton et al. (2011) and Wang et al. (2018), bird species were quantified as rarely/never hunted or killed (0), occasionally hunted or killed (1), and often hunted or killed (2) (see Additional file 1: Appendix S1 for details). Specifically, species were defined as high hunting vulnerability (2) if they were preferred game species, common cage and trade species, or actively persecuted species (e.g. Galliformes, Li and Jiang 2014; Zheng 2015). Bird species were quantified as medium hunting vulnerability (1) if they were not preferred species but were occasionally hunted or killed in related literature ( $\mathrm{Li}$ and $\mathrm{Li} 1998$; Wang et al. 2001; Bi and He 2005; Liang et al. 2013; Dai and Zhang 2015). The remaining species that were rarely or never hunted in any of the above ways were classified as low hunting vulnerability (0) (see Wang et al. 2018 for details). To ensure these traits are appropriate to the scale of the China Species Red List, all the above data were obtained from China literatures, such as Zhuge (1990), Zhao (2001), Zheng (2011) and Liang et al. (2013). For each of the species traits, if a range instead of the mean was given, we used the arithmetic mean of the limits (Gaston and Blackburn 1995).

We also obtained four extrinsic predictors based on hypotheses of published literature (Additional file 1: Appendix S1; Owens and Bennett 2000; Murray et al. 2014). We used the maps of species ranges (Zheng 2011) and global environmental layers to extract the average values of human population density (HPD), temperature, and NDVI (Normalized Difference Vegetation Index) across the geographic range size of each species (Lee and Jetz 2011). We then calculated the mean elevation distribution of each species using its maximum and minimum elevation limits (Li and Pimm 2016). We used mean HPD across the geographic range of each species to reflect anthropogenic impacts (Cardillo et al. 2004). Mean annual temperature is commonly used as a measure of available ambient energy, while NDVI is a proxy for productive environmental energy (Davies et al. 2006). To measure HPD, we used the Gridded Population of the World (CIESIN 2000), a spatially explicit global database of HPD for 2000, coarsened to a resolution of $0.5^{\circ} \times 0.5^{\circ}$ for analyses. Mean annual temperature and NDVI were extracted from the ESRI ARC and GRID software (ESRI 2016).

\section{Statistical analyses}

We employed phylogenetic generalized least squares (PGLS) models to control for the statistical non-independence between species (Orme et al. 2012). Pagel's $\lambda$, a branch length transformation indicating the strength of the phylogenetic signal, was optimized in each model by the maximum likelihood method (Orme et al. 2012). The other two branch length transformations, $\kappa$ and $\sigma$, were set as a constant (1) which assumed a Brownian motion model of evolution (Orme et al. 2012).

To examine the relative roles of biological and extrinsic factors in determining extinction risk, we built a set of relevant PGLS models in three steps. First, we began our analysis by examining the significance of each of the eleven ecological traits and four external factors as predictors of extinction risk separately (Purvis et al. 2000; Jones et al. 2003). Second, we conducted bivariate additive PGLS of each explanatory variable in turn on extinction risk, including range size as the second variable to control for its effect (Purvis et al. 2000; Böhm et al. 2016). Finally, we built all possible combinations of models that included the significant variables in the previous step. We compared model fits and selected models using the Akaike information criterion (AIC) corrected for small sample size (AICc) (Burnham and Anderson 2002). Because our analyses frequently resulted in multiple competing models with a similar AICc, we used model averaging to incorporate model selection uncertainty (Burnham and Anderson 2002). We did not use the traditional stepwise selection procedure because it is inherently flawed in parameter estimation, inconsistent among model selection algorithms and inappropriately focused on a single best model (Whittingham et al. 2006).

Small geographical range size is used as two of the five criteria (criteria B and D2) to assess extinction risk (IUCN 2012a), so any relationship between geographical range and extinction risk could be circular (Cooper et al. 2008). To overcome this problem, the simple method is to exclude species listed as threatened based on small range size (Cooper et al. 2008; Wang et al. 2018). However, we did not use this simple method because range size was the most important predictor of extinction risk (Table 1) and $25.3 \%$ (19) of species would be excluded (Additional file 1: Appendix S1). In contrast, following Böhm et al. (2016), we carried out two additional analyses to avoid the circularity introduced by range size and disentangle its influence on extinction risk. First, we compared the performance of the two best models that included and 
Table 1 Results of one- and two-predictor regressions of independent contrasts for predicting extinction risk in Chinese endemic birds

\begin{tabular}{llllll}
\hline Variable & \multicolumn{2}{l}{ Univariate PGLS } & \multicolumn{2}{c}{$\begin{array}{l}\text { Bivariate PGLS } \\
\text { with range size }\end{array}$} \\
\cline { 2 - 3 } & Slope & $\boldsymbol{t}$ & & Slope & $\boldsymbol{t}$ \\
\hline Body size & 1.086 & $2.469^{*}$ & 1.067 & $2.405^{*}$ \\
Clutch size & -0.167 & $-2.239^{*}$ & -0.176 & $-2.338^{*}$ \\
Trophic level & 0.050 & 0.508 & 0.049 & 0.496 \\
Dispersal ratio & -0.045 & -1.284 & -0.045 & -1.303 \\
Nest type & 0.203 & 0.506 & - & - \\
Nest site & 0.068 & 0.359 & 0.264 & 1.634 \\
Habitat specificity & -0.089 & -1.088 & -0.155 & -1.639 \\
Geographic range size & -0.402 & $3.494^{* * *}-$ & - \\
Flocking & 0.068 & 0.249 & 0.034 & 0.122 \\
Migrant & -0.204 & -0.678 & -0.259 & -0.837 \\
Hunting vulnerability & 0.475 & $3.498^{* * *}$ & 0.469 & $3.409^{* *}$ \\
Human population & 0.001 & $2.597^{*}$ & 0.003 & $3.766^{* * *}$ \\
$\quad$ density & & & & -0.436 \\
Temperature & -0.013 & -0.753 & -0.012 & -0.314 \\
NDVl & -1.160 & -1.203 & $-4.42 \times 10^{-5}$ & -0.314 \\
Elevation & $6.94 \times 10^{-5}$ & 0.626 & 1.325 & 1.045 \\
\hline
\end{tabular}

${ }^{*} p<0.05 ;{ }^{* *} p<0.01 ;{ }^{* * *} p<0.001$

excluded range size (Table 2). In addition, we tested for interactions between range size and each of the above four significant variables. This interaction analysis can check whether once a species is range restricted, additional factors increase in importance to decide whether a range-restricted species is threatened or not (Böhm et al. 2016).

Prior to analyses, all continuous variables were logtransformed to achieve normality. We assessed correlations between variables to determine the potential effect of collinearity on the results of the multivariate analyses (Neter et al. 1996). We retained all the variables for further analyses because none of species traits were highly correlated (Pearson $R<0.60$ ) in our study (Additional file 1: Appendix S2). We fitted PGLS models to the data using the pgls function of the caper package in $\mathrm{R}$ (Orme et al. 2012).

\section{Results}

The pattern of extinction risk in Chinese endemic birds

According to the officially released China Species Red List in 2015, 29 (37.7\%) species of Chinese endemic birds were currently not threatened (Least Concern), $17(22.0 \%)$ were near-threatened, 19 (24.7\%) were vulnerable, 8 (10.4\%) were endangered, $2(2.6 \%)$ were critically endangered, while $2(2.6 \%)$ species were data deficient. Thus, among the 77 Chinese endemic birds,
$29(37.7 \%)$ species were listed as threatened (Vulnerable, Endangered and Critically Endangered) (Additional file 1: Appendix S1).

\section{Correlates of extinction risk in Chinese endemic birds}

The univariate PGLS analyses showed that extinction risk in Chinese endemic birds was significantly associated with large body size, small clutch size, small geographic range size, high hunting vulnerability, and high human population density (Table 1 ). The results remained the same when bivariate additive PGLS was used to control for the effect of geographic range size (Table 1). The best model based on AICc accounted for $46.9 \%$ of total variance, suggesting that endemic species were at a greater risk of extinction if they had small range size $(t=-6.286, p<0.0001)$, high hunting vulnerability $(t=4.496, p<0.0001)$, and exposed to high human population density $(t=5.360, p<0.0001)$ (Table 2, Additional file 1: Appendix S3). However, the Akaike weight $\left(w_{\mathrm{i}}=0.31\right)$ of the best model suggested substantial model selection uncertainty. Relative variable importance, as measured by the sum of Akaike weights $\left(w_{+}\right)$, indicated that geographic range size, hunting vulnerability and human population density were substantially important variables using model averaging in the $95 \%$ confidence set (Table 3). In contrast, body size and clutch size received considerably less support (Table 3).

When excluding geographic range size, model selection based on AICc identified the model incorporating hunting vulnerability $(t=3.897, p=0.0002)$, human population density $(t=2.156, p=0.0345)$ and clutch size ( $t=-2.047, p=0.0444)$ as the best (Table 2, Additional file 1: Appendix S3). However, this model only explained $21.7 \%$ of the variation compared with $46.9 \%$ explained by the best model including range size. In addition, range size interacted significantly with the other four important variables (body size, clutch size, hunting vulnerability and human population density) (Table 4). Therefore, range size played an important role in determining extinction risk of endemic birds.

\section{Discussion}

In this study, we conducted the first extensive analysis to systematically investigate the patterns and processes of extinction and threat in Chinese endemic birds. We found that more than one-third of Chinese endemic birds were listed as threatened. Geographic range size, hunting vulnerability, and human population density were important predictors of extinction risk in Chinese endemic birds. 
Table 2 The performance of PGLS models predicting the extinction risk of Chinese endemic birds

\begin{tabular}{|c|c|c|c|c|c|}
\hline Model description & $\mathrm{K}$ & $\mathrm{AIC}_{\mathrm{c}}$ & $\Delta \mathrm{AIC}_{\mathrm{c}}$ & $w_{\mathrm{i}}$ & Adjusted $R^{2}$ \\
\hline$G R S+H V+H P D$ & 5 & 187.37 & 0.00 & 0.3124 & 0.4693 \\
\hline Body size + GRS + HV + HPD & 6 & 188.16 & 0.79 & 0.2101 & 0.4725 \\
\hline GRS + clutch size + HV + HPD & 6 & 188.47 & 1.11 & 0.1796 & 0.4702 \\
\hline Body size + GRS + clutch size + HV + HPD & 7 & 189.42 & 2.06 & 0.1117 & 0.4727 \\
\hline Body size + GRS + HPD & 5 & 190.62 & 3.25 & 0.0614 & 0.4147 \\
\hline $\mathrm{GRS}+\mathrm{HPD}$ & 4 & 191.14 & 3.77 & 0.0474 & 0.4094 \\
\hline GRS + clutch size + HPD & 5 & 191.40 & 4.04 & 0.0415 & 0.4184 \\
\hline Body size + clutch size + GRS + HPD & 6 & 191.69 & 4.32 & 0.0360 & 0.4179 \\
\hline GRS + clutch size + HV & 5 & 209.70 & 22.34 & $4.40 \times 10^{-6}$ & 0.2823 \\
\hline $\mathrm{GRS}+\mathrm{HV}$ & 4 & 210.58 & 23.21 & $2.85 \times 10^{-6}$ & 0.2620 \\
\hline Body size + clutch size + GRS $+\mathrm{HV}$ & 6 & 211.93 & 24.56 & $1.45 \times 10^{-6}$ & 0.2727 \\
\hline Body size + GRS + HV & 5 & 212.72 & 25.36 & $9.73 \times 10^{-7}$ & 0.2524 \\
\hline Clutch size $+H V+H P D$ & 5 & 216.18 & 28.82 & $1.73 \times 10^{-7}$ & 0.2166 \\
\hline Clutch size + GRS & 4 & 216.32 & 28.95 & $1.61 \times 10^{-7}$ & 0.1661 \\
\hline GRS & 3 & 217.56 & 30.20 & $8.66 \times 10^{-8}$ & 0.1334 \\
\hline Body size + clutch size + GRS & 5 & 217.60 & 30.23 & $8.51 \times 10^{-8}$ & 0.1592 \\
\hline Body size + GRS & 4 & 217.67 & 30.31 & $8.18 \times 10^{-8}$ & 0.1877 \\
\hline $\mathrm{HV}+\mathrm{HPD}$ & 4 & 218.25 & 30.88 & $6.14 \times 10^{-8}$ & 0.1814 \\
\hline Body size + clutch size $+\mathrm{HV}+\mathrm{HPD}$ & 6 & 218.42 & 31.05 & $5.65 \times 10^{-8}$ & 0.2060 \\
\hline Clutch size + HV & 4 & 218.70 & 31.34 & $4.89 \times 10^{-8}$ & 0.1764 \\
\hline Clutch size + HPD & 4 & 219.96 & 32.60 & $2.61 \times 10^{-8}$ & 0.1189 \\
\hline Body size $+\mathrm{HV}+\mathrm{HPD}$ & 5 & 220.41 & 33.04 & $2.08 \times 10^{-8}$ & 0.1705 \\
\hline Body size + clutch size $+\mathrm{HV}$ & 5 & 220.94 & 33.57 & $1.60 \times 10^{-8}$ & 0.1646 \\
\hline $\mathrm{HV}$ & 3 & 221.33 & 33.96 & $1.32 \times 10^{-8}$ & 0.1331 \\
\hline Body size + clutch size + HPD & 5 & 221.69 & 34.32 & $1.10 \times 10^{-8}$ & 0.1090 \\
\hline $\mathrm{HPD}$ & 3 & 222.25 & 34.89 & $8.29 \times 10^{-9}$ & 0.0729 \\
\hline Body size $+\mathrm{HPD}$ & 4 & 222.38 & 35.01 & $7.79 \times 10^{-9}$ & 0.1344 \\
\hline Body size + HV & 4 & 223.50 & 36.14 & $4.44 \times 10^{-9}$ & 0.1212 \\
\hline Clutch size & 3 & 224.24 & 36.87 & $3.07 \times 10^{-9}$ & 0.0521 \\
\hline Body size + clutch size & 4 & 225.95 & 38.58 & $1.31 \times 10^{-9}$ & 0.0413 \\
\hline Body size & 3 & 226.93 & 39.56 & $8.01 \times 10^{-10}$ & 0.0653 \\
\hline
\end{tabular}

The two best models that included and excluded geographic range size were highlighted in italics

GRS geographic range size, HV hunting vulnerability; HPD human population density

Table 3 Model-averaged parameter estimates $(\theta)$, unconditional standard errors (SE) and relative variable importance $\left(w_{+}\right)$for each variable in the $95 \%$ confidence set

\begin{tabular}{|c|c|c|c|c|c|}
\hline Variables & $w_{+}$ & $\theta$ & Unconditional SE & $z$ value & $p$ \\
\hline Intercept & & 4.2405 & 1.1235 & 3.774 & 0.0002 \\
\hline Geographic range size & 1.00 & -0.6664 & 0.1086 & 6.134 & $<2.0 \times 10^{-16}$ \\
\hline Hunting vulnerability & 1.00 & 0.4478 & 0.1508 & 2.970 & 0.0029 \\
\hline Human population density & 0.84 & 0.0026 & 0.0005 & 5.284 & $<1.0 \times 10^{-7}$ \\
\hline Body size & 0.40 & 0.2544 & 0.4465 & 0.570 & 0.5688 \\
\hline Clutch size & 0.35 & -0.0213 & 0.0447 & 0.476 & 0.6339 \\
\hline
\end{tabular}


Table 4 The interaction models between geographic range size and other four important variables (body size, clutch size, hunting vulnerability and human population density)

\begin{tabular}{|c|c|c|c|c|}
\hline & Coefficient & SE & $t$ value & $p$ \\
\hline Range size $\times$ hunting vulnerability & 0.0813 & 0.0278 & 2.922 & 0.0046 \\
\hline Range size $\times$ human population density & 0.0005 & 0.0001 & 3.562 & 0.0007 \\
\hline Range size $\times$ body size & -0.1343 & 0.0457 & -2.936 & 0.0045 \\
\hline Range size $\times$ clutch size & -0.0375 & 0.0119 & -3.144 & 0.0024 \\
\hline
\end{tabular}

In a previous study, Wang et al. (2018) examined the patterns and processes of extinction and threat in all Chinese birds. This present study differs from Wang et al. (2018) in several ways. First, Wang et al. (2018) only considered the intrinsic traits of birds on influencing extinction risk. In this study, however, we included both intrinsic traits and four extrinsic factors (human population density, temperature, NDVI and elevation) to assess their relative roles in determining the extinction risk of Chinese endemic birds. Second, Chinese endemic birds often differ from non-endemic species in many aspects including range size, population sizes, low genetic diversity and specific habitat requirements (Gaston 1994; Isik 2011; Lei and Lu 2006). Accordingly, the results of the two studies were very different: small range size, high hunting vulnerability, and high human population density were important predictors of extinction risk in Chinese endemic birds, while the synergistic interaction between body size and hunting vulnerability was the best correlate of extinction risk in all Chinese birds (Wang et al. 2018). Finally, as this study focuses solely on Chinese endemic birds, the results are important only for their proactive conservation and management efforts.

\section{The pattern of extinction risk in Chinese endemic birds}

We found that $37.7 \%$ of Chinese endemic birds were listed as threatened (Vulnerable, Endangered and Critically Endangered). In contrast, only $10.6 \%$ of all Chinese birds were classified as threatened (146 threatened species out of a total of 1372 species) (Zhang et al. 2016; Wang et al. 2018). Therefore, the proportion of threatened Chinese endemic birds was three times more than that of all Chinese birds. Our results thus support the general claim that endemic species are especially vulnerable to extinction (Gaston 1994; Isik 2011).

\section{Correlates of extinction risk in Chinese endemic birds}

We found that geographical range size was an important predictor of extinction risk in Chinese endemic birds. The variation in extinction risk explained by the best model reduced substantially from 46.9 to $21.7 \%$ when range size was excluded. In addition, range size interacted significantly with the other important variables such as body size, clutch size, hunting vulnerability and human population density. This relationship between range size and extinction risk has previously been observed in amphibians (Cooper et al. 2008), reptiles (Böhm et al. 2016), and mammals (Purvis et al. 2000; Jones et al. 2003). Small range size may increase extinction risk in Chinese endemic birds through reducing the likelihood of population persistence in the face of problems caused by demographic stochasticity, local catastrophes, and inbreeding (Jones et al. 2003; Cooper et al. 2008).

Hunting vulnerability was another important predictor of extinction risk in Chinese endemic birds. Our study found that heavily hunted and persecuted bird species were most likely to become extinct. Similarly, Thornton et al. (2011) showed that mammal species with high hunting vulnerability had high extinction risk due to habitat fragmentation. In our study, phasianids and timaliids are such typical kinds of endangered endemic birds that are subject to direct hunting and exploitation for food, pets, sport and cultural practices (Keane et al. 2005; Liang et al. 2013; Zheng 2015). For these heavily hunted and persecuted bird species, the reduction of hunting pressure should be a primary focus of management efforts in human-dominated environments with high levels of hunting.

Human population density was the best and most consistent environmental predictor of extinction risk in Chinese endemic birds. Human population density represents one of the best available means of summarizing the impact faced by bird and mammal species on a global scale (Cardillo et al. 2004; Davies et al. 2006). At local or regional scales, high human population density is also associated with species decline or extinction (Woodroffe 2000; Brashares et al. 2001; McKinney 2001). Chinese endemic birds with ranges exposed to high human population density were at a greater risk of extinction because these regions are more likely to be affected by anthropogenic threats, such as habitat loss, hunting and exploitation.

Our study provided mixed evidence for the effect of body size on extinction risk in Chinese endemic birds. Body size was significantly associated with extinction risk 
in the single-predictor and bivariate phylogenetic analyses, but received considerably less support in the best model after controlling for other factors. In general, the effects of body size on extinction risk are arguable based on current empirical evidence (Gaston and Blackburn 1995). There are at least two reasons that may explain why the relationship between body size and extinction risk is equivocal. First, body size is correlated with variables that are themselves positively and negatively correlated with extinction risk (Lawton 1994). Moreover, the relationship of body size to several variables (e.g. species abundance) seems to change dramatically at different taxonomic levels (Nee et al. 1991).

Owens and Bennett (2000) demonstrate that bird species endangered by habitat loss have different biological traits from those endangered by human persecution and introduced predators. Our understanding of the mechanisms that link species biology with extinction risk would be improved if comparative analyses can be conducted according to different extrinsic threats (Owens and Bennett 2000; Murray et al. 2014). However, in our study, the majority of Chinese endemic birds (89.7\%) are threatened either by habitat loss and degradation alone or by habitat loss and degradation and human persecution together, while none was threatened by human persecution alone. Thus, the nature of our data prevents us from analyzing whether ecological traits of Chinese endemic birds endangered by habitat loss are different from those endangered by human persecution.

\section{Conclusions}

Comparative phylogenetic analyses can contribute to conservation prioritization by identifying species that possess extinction-promoting traits. We found that biological (geographical range size, hunting vulnerability) and environmental (human population density) factors are key to predicting extinction risk in Chinese endemic birds. These findings have important implications with regard to conservation practices. First, Chinese endemic birds with small geographical range size should be the conservation priority as these species have high extinction risk (Purvis et al. 2000; Jones et al. 2003; Böhm et al. 2016). In addition, our study highlights the importance of anthropogenic influences on extinction risk (Cardillo et al. 2004; Davies et al. 2006). Chinese endemic species with high hunting vulnerability and high exposure to human population density are particularly vulnerable to extinction. To effectively conserve these threatened endemic species, the reduction of anthropogenic threats, such as habitat loss, hunting and exploitation, should be a primary focus of management efforts. To sum up, conservation efforts giving priority to species with small range size, high hunting vulnerability, and high exposure to human population density may prove effective for the preservation of Chinese endemic birds.

\section{Additional file}

Additional file 1: Appendix S1. Ecological traits and extinction risk of Chinese endemic birds. Appendix S2. The correlation matrix for ecological traits of Chinese endemic birds. Appendix S3. The two best models predicting the extinction risk of Chinese endemic birds.

\section{Authors' contributions}

YW conceived the study. CC, DZ, YZ, YW and JX collected the data. YW and CC performed the analyses. CC and YW wrote the first draft of the paper. All authors read and approved the final manuscript.

\section{Author details}

1 Jiangsu Key Laboratory for Biodiversity and Biotechnology, College of Life Sciences, Nanjing Normal University, Nanjing 210023, China. ${ }^{2}$ College of Life Sciences, Zhejiang University, Hangzhou 310058, China. ${ }^{3}$ Institute of Remote Sensing and Earth Sciences, Hangzhou Normal University, Hangzhou 311121, China.

\section{Acknowledgements}

We thank the anonymous reviewers for valuable comments on previous version of the manuscript.

\section{Competing interests}

The authors declare that they have no competing interests. The funders have no role in study design, data collection and analysis, decision to publish, or preparation of the manuscript.

\section{Availability of data and materials}

All data generated or analyzed during this study are included in this published article [and its Additional file].

\section{Consent for publication}

Not applicable.

Ethics approval and consent to participate

Not applicable.

\section{Funding}

This study was supported by the National Natural Science Foundation of China (31100394, 31471981 and 31770462 to WY), Zhejiang Provincial Natural Science Foundation (LZ18C030002 to WY), and China Scholarship Council (201506320019 to CC).

Received: 4 November 2018 Accepted: 11 March 2019

Published online: 16 March 2019

\section{References}

Barbaro L, van Halder I. Linking bird, carabid beetle and butterfly life-history traits to habitat fragmentation in mosaic landscapes. Ecography. 2009;32:321-33.

Beauchamp G. Reduced flocking by birds on islands with relaxed predation. Proc R Soc Lond B Biol Sci. 2004;271:1039-42.

Bennett PM, Owens IPF. Variation in extinction risk among birds: chance or evolutionary predisposition? Proc R Soc Lond B Biol Sci. 1997;264:401-8.

Bi J, He X. An investigation on the trade of wild birds market in Huhhot. J Inner Mongolia Normal Univ (Nat Sci). 2005;34:93-101 (in Chinese).

Böhm M, Williams R, Bramhall HR, McMillan KM, Davidson AD, Garcia A, Bland LM, Bielby J, Collen B. Correlates of extinction risk in squamate reptiles: 
the relative importance of biology, geography, threat and range size. Glob Ecol Biogeogr. 2016;25:391-405.

Brashares JS, Arcese P, Sam MK. Human demography and reserve size predict wildlife extinction in West Africa. Proc R Soc Lond B Biol Sci. 2001;268:2473-8.

Burnham KP, Anderson DR. Model selection and multimodel inference: a practical information-theoretic approach. 2nd ed. New York: Springer; 2002.

Cardillo M, Purvis A, Sechrest W, Gittleman JL, Bielby J, Mace GM. Human population density and extinction risk in the world's carnivores. PLoS Biol. 2004;2:909-13.

Cardillo M, Mace GM, Gittleman JL, Jones KE, Bielby J, Purvis A. The predictability of extinction: biological and external correlates of decline in mammals. Proc R Soc Lond B Biol Sci. 2008;275:1441-8.

Collen B, Bykova E, Ling S, Milner-Gull EJ, Purvis A. Extinction risk: a comparative analysis of Central Asian vertebrates. Biodivers Conserv. 2006;15:1859-71.

Cooper N, Bielby J, Thomas GH, Purvis A. Macroecology and extinction risk correlates of frogs. Glob Ecol Biogeogr. 2008;17:211-21.

Dai C, Zhang G. Status of local bird trade in Guiyang city during the breeding season. Sichuan J Zool. 2015;34:306-11 (in Chinese).

Darlington PJ. Zoogeography: the geographical distribution of animals. New York: Wiley; 1957.

Davies RG, Orme CDL, Olson V, Thomas GH, Ross SG, Ding T-S, Rasmussen PC, Stattersfield AJ, Bennett PM, Blackburn TM, Owens IPF, Gaston KJ. Human impacts and the global distribution of extinction risk. Proc R Soc Lond B Biol Sci. 2006;273:2127-33.

Drummond AJ, Rambaut A. BEAST: Bayesian evolutionary analysis by sampling trees. BMC Evol Biol. 2007;7:214.

ESRI (Environmental Systems Research Institute). ArcGIS desktop 10.2. Redlands: Environmental Systems Research Institute; 2016.

Fisher DO, Bloomberg SP, Owens IPF. Extrinsic versus intrinsic factors in the decline and extinction of Australian marsupials. Proc R Soc Lond B Biol Sci. 2003;270:1801-8.

Gaston KJ. Rarity. London: Chapman \& Hall; 1994.

Gaston KJ, Blackburn TM. Birds, body size and the threat of extinction. Philos Trans R Soc Lond B Biol Sci. 1995;347:205-12.

Isaac NJB, Cowlishaw G. How species respond to multiple extinction threats, Proc R Soc Lond B Biol Sci. 2004;271:1135-41.

Isik K. Rare and endemic species: why are they prone to extinction? Turk J Bot. 2011;35:411-7.

IUCN. IUCN red list categories and criteria: version 3.1. 2nd ed. Gland: IUCN; 2012a.

IUCN. Guidelines for application of IUCN red list criteria at regional and national levels, version 4.0. Gland: IUCN; 2012b.

Jetz W, Thomas GH, Joy JB, Hartmann K, Mooers AO. The global diversity of birds in space and time. Nature. 2012;491:444-8.

Jones KE, Purvis A, Gittleman JL. Biological correlates of extinction risk in bats. Am Nat. 2003;161:601-14.

Keane A, de Brooke ML, McGowan PJK. Correlates of extinciton risk and hunting pressure in gamebirds (Galliformes). Biol Conserv. 2005;126:216-33.

Lawton JH. Population dynamic principles. Philos Trans R Soc Lond B Biol Sci. 1994;344:61-8.

Lee TM, Jetz W. Unravelling the structure of species extinction risk for predictive conservation science. Proc R Soc Lond B Biol Sci. 2011;278:1329-38.

Lei F, Qu Y, Lu J, Liu Y, Yin Z. Conservation on diversity and distribution patterns of endemic birds in China. Biodivers Conserv. 2003a;12:239-54.

Lei F, Qu Y, Tang Q, An S. Priorities for the conservation of avian biodiversity in China based on the distribution patterns of endemic bird genera. Biodivers Conserv. 2003b;12:2487-501.

Lei F, Lu T. China endemic birds. Beijing: Science Press; 2006.

Li BV, Pimm SL. China's endemic vertebrates sheltering under the protective umbrella of the giant panda. Conserv Biol. 2016;30:329-39.

Li L, Jiang Z. International trade of CITES listed bird species in China. PLoS ONE. 2014;9:e85012

LiY, Li D. The dynamics of trade in live wildlife across the Guangxi border between China and Vietnam during 1993-1996 and its control strategies. Biodivers Conserv. 1998;7:895-914.

Liang W, Cai Y, Yang C. Extreme levels of hunting of birds in a remote village of Hainan Island, China. Bird Conserv Int. 2013;23:45-52.

McKinney ML. Role of human population size in raising bird and mammal threat among nations. Anim Conserv. 2001:4:45-57.
MEP (The Ministry of Environment Protection) and CAS (the Chinese Academy of Sciences). Redlist of China's biodiversity: birds. 2015. http:// www.zhb.gov.cn/gkml/hbb/bgg/201505/W0201505265819392123 92.pdf. Accessed 22 May 2015.

Milner-Gulland EJ, Kreuzberg-Mukhina E, Grebot B, Ling S, Bykova E, Abdusalamov I, Bekenov A, Gärdenfors U, Hilton-Taylor C, Salnikov V, Stogova L. Application of IUCN red listing criteria at the regional and national levels: a case study from Central Asia. Biodivers Conserv. 2006;15:1873-86.

Murray KA, Verde Arregoitia LD, Davidson A, Di Marco M, Di Fonzo MM. Threat to the point: improving the value of comparative extinction risk analysis for conservation action. Glob Change Biol. 2014;20:483-94.

Myers N, Mittermeier RA, Mittermeier CG, da Fonseca GAB, Kent J. Biodiversity hotspots for conservation priorities. Nature. 2000;403:853-8.

Nee S, Read AF, Greenwood JJD, Harvey PH. The relationship between abundance and body size in British birds. Nature. 1991;351:312-3.

Neter J, Kutner MH, Nachtsheim CJ, Wasserman W. Applied linear statistical model: regression, analysis of variance, and experimental design. Chicago: Irwin Professional Publishing; 1996.

Newbold T, Scharlemann JPW, Butchart SHM, Sekercioglu CH, Alkemade $\mathrm{R}$, Booth $\mathrm{H}$, Purves DW. Ecological traits affect the response of tropical forest bird species to land-use intensity. Proc R Soc Lond B Biol Sci. 2013;280:2012-131.

Orme D, Freckleton R, Thomas G, Petzoldt T, Fritz S, Isaac N, Pearse W. CAPER: comparative analyses of phylogenetics and evolution in R. R package version 0.5. 2012. http://CRAN.R-project.org/package=caper. Accessed 11 Nov. 2017.

Owens IP, Bennett PM. Ecological basis of extinction risk in birds: habitat loss versus human persecution and introduced predators. Proc Natl Acad Sci USA. 2000;97:12144-8.

Purvis A, Gittleman JL, Cowlishaw G, Mace GM. Predicting extinction risk in declining species. Proc R Soc Lond B Biol Sci. 2000;267:1947-52.

Rabitsch W, Graf W, Huemer P, Kahlen M, Komposch C, Paill W, Reischutz A, Reischutz PL, Moser D, Essl F. Biogeography and ecology of endemic invertebrate species in Austria: a cross-taxon analysis. Basic Appl Ecol. 2016;17:95-105.

Sekercioglu CH, Daily GC, Ehrlich PR. Ecosystem consequences of bird declines. Proc Natl Acad Sci USA. 2002;101:18402-7.

Sodhi NS, Wilcove DS, Lee TM, Sekercioglu CH, Subaraj R, Bernard H, Yong DL, Lim SLH, Prawiradilaga DM, Brook BW. Deforestation and avian extinction on tropical landbridge islands. Conserv Biol. 2010;24:1290-8.

Terborgh J. Preservation of natural diversity: the problem of extinction prone species. Bioscience. 1974;24:715-22.

Thornton D, Branch L, Sunquist M. Passive sampling effects and landscape location alter associations between species traits and response to fragmentation. Ecol Appl. 2011;21:817-29.

Van Houtan KS, Pimm SL, Bierregaard RO Jr, Lovejoy TE, Stouffer PC. Local extinctions in flocking birds in Amazonian forest fragments. Evol Ecol Res. 2006;8:129-48.

Van Turnhout CAM, Foppen RPB, Leuven RSEW, Van Strien A, Siepel H. Lifehistory and ecological correlates of population change in Dutch breeding birds. Biol Conserv. 2010;143:173-81.

Wang J, Ye S, He Y, Xu X. Species and trade of ornamental birds in Shnaghai, Nanjing, Suzhou, Wuxi and Yangzhou. Mod Anim Husb. 2001:4:38-9 (in Chinese).

Wang Y, Thornton DH, Ge D, Wang S, Ding P. Ecological correlates of vulnerability to fragmentation in forest birds on inundated subtropical land-bridge islands. Biol Conserv. 2015;191:251-7.

Wang Y, Si X, Bennett PM, Chen C, Zeng D, Zhao Y, Wu Y, Ding P. Ecological correlates of extinction risk in Chinese birds. Ecography. 2018;41:782-94.

Whittingham MJ, Stephens PA, Bradbury RB, Freckleton RB. Why do we still use stepwise modelling in ecology and behaviour? J Anim Ecol. 2006;75:1182-9.

Wilcove DS. Nest predation in forest tracts and the decline of migratory songbirds. Ecology. 1985;66:1211-4.

Woinarski JCZ. Some life history comparisons of small leaf-gleaning bird species of south-eastern Australia. Corella. 1989;13:73-80.

Woodroffe R. Predators and people: using human densities to interpret declines of large carnivores. Anim Conserv. 2000;3:165-73.

Zhang Y, Zhang Z, Dong L, Ding P, Ding C, Ma Z, Zheng G. Assessment of red list of birds in China. Biodiv Sci. 2016;24:568-77 (in Chinese). 
Zhao Z. A handbook of the birds of China. Changchun: Jilin Science and Technology Publishing House; 2001 (in Chinese).

Zheng G. A checklist on the classification and distribution of the birds of China. Beijing: Science Press; 2011 (in Chinese).
Zheng G. Pheasant in China. Beijing: Higher Education Press; 2015 (in Chinese).

Zhuge Y. Fauna of Zhejiang: aves. Hangzhou: Zhejiang Science and Technology Publishing House; 1990 (in Chinese).
Ready to submit your research? Choose BMC and benefit from:

- fast, convenient online submission

- thorough peer review by experienced researchers in your field

- rapid publication on acceptance

- support for research data, including large and complex data types

- gold Open Access which fosters wider collaboration and increased citations

- maximum visibility for your research: over 100M website views per year

At BMC, research is always in progress.

Learn more biomedcentral.com/submissions 